\title{
Setting our Cites on Gender: Toward Development of Inclusive Scholarly Support Services for All Faculty
}

\author{
Laura Robinson and Anna Newman \\ Worcester Polytechnic Institute, USA
}

\begin{abstract}
Understanding gendered practices and biases in scholarly communication can help librarians develop the right mix of relevant faculty support to encourage diversity, equity, and inclusion on our campuses, while contributing to broader work in strengthening equity in research practices. A number of recent studies explore gender differences and biases in peer-review ${ }^{1}$ and citation practices, ${ }^{2}$ which are key issues for librarians to consider when providing services in these areas. This work reports on a study to understand gender-specific faculty practices throughout the research and scholarly lifecycle, with particular focus on awareness of and attitudes toward online research profile development, open access, and citation metrics and practices. We completed brief structured interviews with 20 faculty across disciplines and at varied points on the career trajectory, divided evenly by gender identification, in order to understand the following: Are there differences by gender in what scholarly profiles and social media accounts faculty wish to maintain? Which impact measures are prioritized, and how and why are these profiles and measures used? What motivates faculty to participate in open access publishing, or what are the deterrents? Considering the answers to these questions, how do librarians best market and deliver the appropriate services as we struggle for funding and time? Results showed that our male subjects were more active in the areas we explored while several women indicated hesitancy to engage in scholarly online profile building due to personal security and privacy issues based on being female. Female subjects had direct examples of gender biases they or their colleagues had experienced, whereas several male subjects acknowledged biases but were not aware of particular examples in their disciplines. Few subjects of either gender deemed traditional impact measures as an accurate reflection of the importance of their work, and most subjects suggested measures that would be more meaningful and more customized to illustrate real-world value. This study has illustrated the array of faculty needs on our campus as well as the array of mindsets and gendered experiences that we must consider when providing faculty research services; future work exploring gendered practices by discipline and faculty rank will further elucidate these considerations.
\end{abstract}

\section{Introduction}

This study focuses on exploring gendered issues related to scholarly communication practices, including attitudes toward development of an online professional and scholarly identity, open access, and measures of professional and scholarly impact. As university librarians, we are in a unique position to understand the needs and practices of scholars on our campuses. Indeed, through many decades, librarians have built liaison relationships and supported a plethora of services cutting across disciplines and built through crossdisciplinary collaborations and feedback. As emerging research indicates gender inequities in publication, citation, and impact measures, it behooves the library community to take a closer look at the practices of female, male, non-binary, and transgendered scholars in our communities. When the library has a better understanding of gendered scholarly practices, we can build more effective services better tailored to individual needs, rather than driven by the pressures of information providers promoting specific services or products. Developing services that address existing biases has the potential to improve the professional prospects of researchers and promote equity within the scholarly communications system. More broadly, increased diversity in teams, including gender diversity, can result in better science or problem solving on both small and large scales, as evidenced by many compelling studies. ${ }^{3}$

\section{Literature Review}

\subsection{Online Presence}

There is considerable literature reviewing gendered behavior online but little when it comes to online presence for faculty branding and profile building. With the prevalence of Academia.edu and ResearchGate, 
despite copyright concerns, as well as the importance of commercial profile systems such as Google Scholar and Elsevier's Scopus IDs, online presence or "Professorial Branding"" is becoming a standard part of academic life. Kendall, Yee, and Hardy's 2017 article title declares "We should be just a number and we should embrace it," and discusses potential benefits of universal adoption of tools such as ORCID. ${ }^{5}$ ORCID is important for name-disambiguation, and is being embedded or required in various places throughout the scholarly lifecycle. ${ }^{6}$ However, there is little discussion of how gender plays a role in ORCID or any of the profile systems described above. Meier and Tunger's 2018 study of scientists' opinions and usage of ResearchGate concluded that, of the factors of origin, age, discipline, and gender, gender had the least influence on respondents' reported attitudes. ${ }^{7}$ They found that women thought ResearchGate required less effort to use and made more sense as a scientist than did men. Additionally, prior to beginning our research, we were aware through our practices that female academics often spend considerable time trying to correct their online presence, due to name changes through marriage or divorce, particularly when they submit tenure, promotion, grant, and other applications. Little research addresses this issue.

\subsection{Open Access}

While there have been multiple studies surveying scholars' attitudes toward open access, there has been very little research examining gendered behavior in approaches to open access. ${ }^{8}$ One study by Zhu in 2017 examined a variety of demographic factors, including gender, associated with open access practices among United Kingdom academics, finding that men were slightly more likely to have participated in gold and green open access publishing than were women. ${ }^{9}$ Segado-Boj, Martín-Quevedo, and Prieto-Gutiérrez's 2018 study surveying contributors to Spanish academic journals found that age and years of career experience had more of an influence than gender on attitudes towards open access. ${ }^{10}$

\subsection{Impact Measures and Citation Practices}

A variety of studies have established that female and male researchers publish at different rates and are cited at different rates, with the advantage in most reported cases being on the side of male researchers. ${ }^{11} \mathrm{~A}$ number of researchers have explored gender bias in publication, peer review, and citation, and have completed in-depth analyses of trends in these areas, with some showing cautious optimism that equity may be possible in the coming years. Van den Besselaar and Sandstrom, in their 2017 study of scholarly productivity and impact differences between men and women at Swedish universities, found that higher productivity classes of researchers are generally dominated by men and that women tend to have lower academic rank and are more likely to be middle authors rather than first authors on publications, thereby creating what the authors refer to as "vicious circles of gender bias, lower positions, and lower performance." 12

There have been a number of studies exploring gender bias in peer-review. For example, Kaatz, Gutierrez, and Carnes' 2014 work, "Threats to objectivity in peer-review: the case of gender," cites a body of work going as far back as 1968 that explores bias against women in various areas of society and particularly in academic life and scholarly communication. ${ }^{13}$ Helmer, Schottdorf, Neef, and Demian's 2017 study of gender bias in the peer-review process presents same-gender preference as a human pattern at work and states that even after there is equity among the genders, other efforts will be needed to challenge partisanship and discrimination in the scientific community. ${ }^{14}$

Self-citation is also an area where gender plays a role. King, Bergstrom, Correll, Jacquet, and West found, in their 2017 study, that male authors of papers they examined over a 20 -year period were $70 \%$ more likely to cite their own work than were women. They were, however, unable to determine whether the self-citation gap is a cause or a consequence of gender imbalances in academia. ${ }^{15}$

\subsection{Library Services to Faculty}

While there is extensive literature about academic library liaison service models to faculty, there is little research exploring gender differences in this area. One study of universities in Bangladesh found that there was no difference in satisfaction with online library subscription resources between male and female 
faculty. ${ }^{16}$ However, there have been a number of studies exploring mentorship of female faculty in an attempt to increase the number of females in senior faculty positions. ${ }^{17}$

\section{Methods}

Our study subjects were chosen from a pool of faculty respondents who had completed a library services survey during the academic year of 2017-2018 and who responded to that survey indicating willingness to provide further feedback on library-related issues. We sought a full picture of faculty at our institution, so we invited faculty at all ranks, including non-tenure track, and across disciplines. We invited faculty to 30minute interviews to be held between June and September of 2018. We sought 10 male and 10 female subjects. We had no faculty subjects who identified as non-binary or transgender from the original pool of possible subjects. Eighteen subjects completed the interview in person while two responded by phone. Both researchers completed 18 of the 20 interviews, while two were completed by only one of the researchers. Notes from both researchers were consolidated and analyzed using Qualtrics. The intention of our study was to view each subject as a case study, so the analysis through Qualtrics was intended to identify trends on our campus rather than statistically significant results.

Interview questions were as follows:

Scholarly Profiles/Online Presence

1. What scholarly profiles do you maintain?

2. What scholarly profiles have you heard of?

3. Why do you maintain these profiles?

4. What deters you from creating these profiles?

Social Media Practices

5. What social media do you use for your personal life?

6. What social media do you use for your professional life?

7. What social media do you use to share news or updates about your work, or to find news or updates related to your research area?

Impact Measurement

8. Which impact measures, if any, do you check frequently?

9. Which impact measures are important to you professionally?

10. If you could tell your own story of the impact of your work, what kinds of data would be the most meaningful to you?

Open Access

11. Have you made any of your works available open access, and how?

12. Why do you make your works publicly available?

13. What deters you from making your works publicly available? 


\section{Library Support}

14. How do you currently learn about the above services/topics?

15. What types of support would you want in the above?

16. What formats of support would you prefer?

Gender

17. What, if any, impact does gender have on the above practices, in your experience?

At the completion of all interviews we determined to omit analysis for questions 2 and 5 due to ambiguity in how the questions were phrased.

\section{Results}

\subsection{Online Presence}

Understanding if and how faculty across genders value online profile building systems, such as ORCID, ResearcherID, and LinkedIn, is key to marketing these services on our campuses. The most common reasons our subjects cited for not maintaining profiles were lack of time and lack of understanding of the value of some of the tools.

Our female subjects maintain a total of 18 profiles online, averaging about two profiles each, while male respondents maintain a total of 29 profiles, or about three profiles each. One possible reason for this difference in adoption rates is that four of the five people who cited privacy concerns as a deterrent to creating profiles were female. Two of our female subjects described situations where they or a close friend were targeted online due to opinions expressed through or about their academic work. One female respondent also expressed concern about whether a university has protections in place if she were to be threatened online. Two other females shared that cultural norms had taught them that it was not appropriate to put themselves forward as experts. In contrast, two male respondents indicated that creating profiles online and making themselves highly findable was, without question, part of the job of being an academic.

Despite its reputation as a professional rather than an academic tool, LinkedIn was the most commonly used platform, with 11 (six male, five female) of the 20 respondents maintaining profiles there. Respondents indicated that LinkedIn is a good way to recruit postdoctoral scholars and part-time faculty, and to develop industry connections for project collaborations and job and internship contacts for their undergraduates. Because of these practical outcomes, respondents were able to see the clear return on their time investment for developing a LinkedIn account.

Six faculty maintain ResearchGate profiles, but only one of the six is female. Two males and three females maintain Academia.edu profiles, and only four respondents maintain a Google Scholar or ORCID profile (three male, one female for each profile). Other types of online profiles that are maintained less frequently by male and female respondents are ResearcherID, Scopus ID, Bepress Expert Gallery, Twitter, and personal and lab websites, though two (one male and one female) curate their lab websites extensively and use them as one of their primary places to attract collaborators, share research, and promote their work to a broader audience. See Figure 1 for a complete breakdown by gender. 
Figure 1: Online Profiles Maintained, by Gender

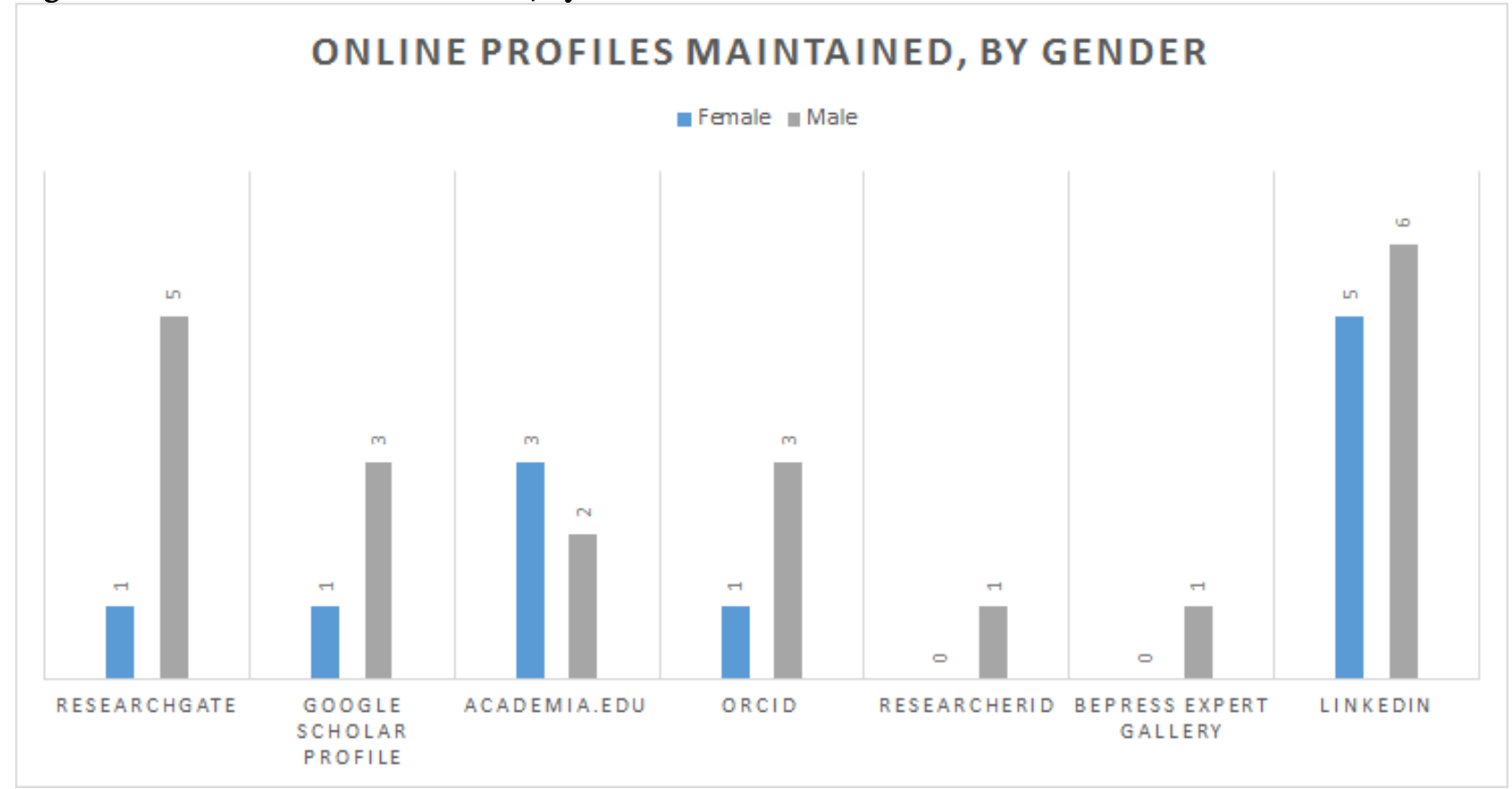

One male subject reported that his Google Scholar profile is how people find him and that he had a "very low opinion" of a researcher if they did not maintain a Google Scholar profile. In contrast, another male subject with high publication rates did not rate highly the quality of the Google Scholar search for his discipline and therefore was unwilling to consider having a profile there.

One female subject stated that her lab website was her personal website, even though the website highlighted both her own work and the work of others in her lab. However, there seem to be benefits for individuals in creating their own academic brand, so this may be a reason to encourage those with only lab websites to consider further online profile development.

Reasons that cut across gender in favor of maintaining profiles were unsurprisingly about finding academic positions and achieving tenure. Two male respondents cited their online presence as a way to attract the attention of grant reviewers. Interestingly, three males mentioned maintaining profiles in order to connect with former students, track former students' success in the workplace, or to help their students find jobs.

\subsection{Open Access}

Male and female subjects reported similar types of open access activity, but the subjects who were most actively engaged in making their work openly available were male. Individual male subjects reported (1) paying as many article processing charges (APCs) to publish his work open access as his funding would support; (2) uploading all his work to an institutional repository; and (3) posting all his work on his lab website.

Female subjects described more cautious approaches to sharing their work publicly, characterized by isolated activity, rather than sustained efforts. Individual female subjects reported (1) sharing raw files when others asked for them; (2) sharing only her teaching materials on her personal website; (3) posting one article on a scholarly profile after being "cajoled" by a colleague; and (4) posting a couple of photos of her work on her personal website. The most active female subject shared that open access was mandated by her funders so all of her articles were openly available. 
There were also differences in the factors that male and female subjects reported as deterring them from making their work publicly available. Male subjects attributed their lack of open access activity to reasons relating to the mechanics of gold or green open access: copyright concerns, concerns about journal quality, lack of time and knowledge, not wanting earlier versions to be distributed, and limitations due to publisher policy.

While some female subjects expressed similar concerns, many subjects reported reasons relating to the concept of open access in general. Several subjects could not see a reason why others outside of a targeted group, such as WPI students or professional society members, would benefit from reading their work.

Several female subjects used words expressing a lack of confidence in their work when asked about it being made available openly. One subject characterized her work as "not original" and did not consider that wider audiences would find it beneficial. Another subject expressed extreme reticence for others to read her work. She related a story about meeting a distinguished scholar who was reading one of her books. She instantly said to him, "Please don't read my book!" She stated that her goal is not to be an "academic superstar," so she did not see how open access would benefit her. One female respondent claimed that her work was not good enough to be open access, while, in contrast, another claimed her work was not good enough to be behind a publisher pay wall.

Female subjects were also more likely than male subjects to express concerns about copyright and the security of their work. Four out of the ten females interviewed expressed concerns about copyright as limiting what they make openly available. One subject only shares her teaching materials because those are the materials of which she is certain she holds the copyright. In contrast, male subjects acknowledged concerns about copyright, but were more comfortable overall in making judgments about how they could share their published work.

Three female subjects expressed concern for the security of their work. One subject shared that she does not put her course syllabus in WPI's course management system because the system could be hacked and her syllabus stolen and sold. Another subject shared that someone once posted her lesson plan online, and her department head contacted this person to ask them to take it down. A third subject expressed concern that her work would be misrepresented or misquoted if she made it openly available. Of the male subjects, only one mentioned security concerns as a deterrent from open access, as his work is proprietary.

\subsection{Impact Measurement}

There were low to medium levels of use for standard impact measurements, such as impact factor, citation counts, and h-index, among the 20 subjects. Figure 2 shows the number of subjects, by gender, who considered a particular metric important to them professionally: 
Figure 2: Impact measures considered important to subjects, by gender.

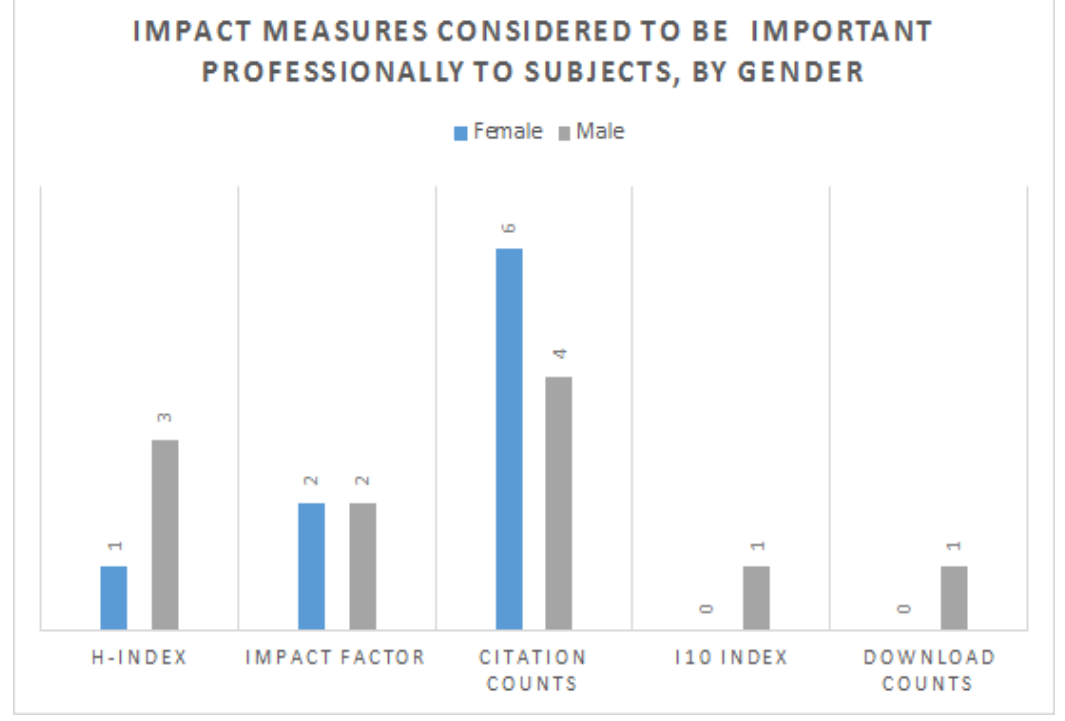

While these questions may seem most applicable to tenured or tenure track faculty, libraries must adapt to the fact that tenure-eligible positions are no longer the majority of faculty positions in academia in the United States. A 2013 report by Kezar and Maxey points out that, while in 1969, only $21.7 \%$ of faculty were non-tenure track, in 2009 in the United States, $66.5 \%$ of faculty are in academic positions where they are ineligible for tenure. ${ }^{18}$ While traditional impact metrics, such as citation counts, are still important to those on the tenure track or aspiring to be so, there are many faculty on our campuses who are working to make a difference through research and teaching, even though they may not receive the privileges of tenure. These tenure-ineligible faculty may be the drivers of new ways to measure impact that are not dependent on the tenure cycle, so it behooves librarians and all in higher education to pay attention to their needs.

To get to the heart of what our diverse subjects, both on and off the tenure track, cared about in terms of impact, we asked them to respond to the following question and received compelling and complex answers: "If you could tell your own story of the impact of your work, what kinds of data would be the most meaningful to you?" Table 1 provides a list of summarized responses, not for the purpose of quantifying whether males or females are more interested in which types of data, but to show the diversity of ways that faculty across gender consider impact.

Table 1: Responses by gender to the question: If you could tell your own story of the impact of your work, what kinds of data would be the most meaningful to you?

\begin{tabular}{|c|c|}
\hline Responses from Female Subjects & Responses from Male Subjects \\
\hline $\begin{array}{l}\text { - } \begin{array}{l}\text { Evidence of positive impact on society } \\
\text { educators }\end{array} \\
\text { - } \begin{array}{l}\text { Evidence of positive impact on society } \\
\text { Evidence of students' post-graduation } \\
\text { success }\end{array}\end{array}$ & $\begin{array}{l}\text { Student learning outcomes metrics } \\
\text { - }\end{array}$ \\
\hline underrepresented students
\end{tabular}




\begin{tabular}{|c|c|}
\hline Responses from Female Subjects & Responses from Male Subjects \\
\hline $\begin{array}{l}\text { - Evidence of being acknowledged as expert by } \\
\text { those in field }\end{array}$ & $\begin{array}{l}\text { - Appearances in the media } \\
\text { - Count of times his work is mentioned by } \\
\text { scholars and non-scholars }\end{array}$ \\
\hline - Evidence of libraries collecting her work & $\begin{array}{l}\text { - Invitations to speak in academic departments } \\
\text { - Positive reviews by grant reviewers }\end{array}$ \\
\hline $\begin{array}{l}\text { - Evidence of impact on policy makers } \\
\text { - Speaker invitations to conference and group } \\
\text { events both in and outside her professional } \\
\text { circles } \\
\text { - Evidence of teaching enabling her students to } \\
\text { question their own perspectives }\end{array}$ & $\begin{array}{l}\text { Evidence of work resulting in useful standards } \\
\text { or products }\end{array}$ \\
\hline - $\quad$ Evidence of impact on policy makers & - Student learning outcomes \\
\hline $\begin{array}{ll}\text { - } & \text { Number of publications } \\
\text { - } & \text { Impact Factor of journals } \\
\text { - } & \text { Citation counts }\end{array}$ & $\begin{array}{l}\text { - } \quad \text { Program accreditation } \\
\text { - Students' professional success } \\
\text { - Whether students keep in touch past graduation }\end{array}$ \\
\hline $\begin{array}{l}\text { Evidence of exposure among non-scholars, } \\
\text { especially disadvantaged communities who } \\
\text { could benefit from her work } \\
\text { - Web page download analytics }\end{array}$ & $\begin{array}{l}\text { - Evidence of positive impact on communities } \\
\text { and society }\end{array}$ \\
\hline $\begin{array}{l}\text { - Number of publications } \\
\text { - } \quad \text { Evidence of impact on society }\end{array}$ & $\begin{array}{l}\text { - Invitations to edit works in area of expertise } \\
\text { - Evidence of students being able to think and } \\
\text { write better as a result of his teaching }\end{array}$ \\
\hline
\end{tabular}

The responses above generally reflect four categories of desirable data: those reflecting (a) success in student outcomes both during college and after graduation, (b) academic productivity or personal prestige, (c) societal impact, and (d) impact on other educators. While no patterns are discernable based on gender, this set of answers gives a sense of how limiting citation metrics are when it comes to the important work our faculty are doing, and that while citation metrics may be required, other measures of impact are more highly valued by the majority of our respondents. This is a keen reminder that, as librarians, we should avoid assumptions about how our faculty measure their own impact. Hearing stories from 20 diverse faculty voices showed us that creative services to faculty may indeed be most welcomed as many in academia work to change the discourse around the definition of impact.

\subsection{Library Services to Faculty}

When asked about the format of services that faculty would most appreciate for learning about the topics discussed, nine of the 20 respondents were enthusiastic about personalized one-on-one support, with one mentioning a desire for an "annual check-up," with customized recommendations of services. Few respondents were interested in other specific types of support. Only four were interested in workshops and suggested that they would be interested if the workshops were truly hands-on (e.g., come to this workshop and leave with your ORCID) or customized for affinity groups (e.g. women, social scientists, etc.). Four subjects were interested in online tutorials either as stand-alone resources or in conjunction with personalized help. Unsurprisingly, the overarching message from faculty was that individual contact and personalization were highly valued; there was no apparent difference based on gender. 


\subsection{Gender}

The final question we asked of our subjects was, "What, if any, impact does gender have on the above practices, in your experience?" Three males and one female responded that they did not feel gender impacted any of the topics discussed, with one male asking, "What could gender possibly have to do with it?" Four respondents (one male and three females) stated that they did not know if it had an impact.

Six out of the ten female subjects believed that gender had a definite impact on the topics they were interviewed about. Online harassment was evoked by four female subjects, who mentioned how women were more likely than men to experience online harassment, especially if they create a public profile. One subject said, "I worry [about having a public profile] more than a male colleague who's just doing research." She mentioned research showing that women are more likely to be attacked, bullied, or targeted online and stated that she believes that universities are unprepared to deal with these consequences. Another subject mentioned that social media has a "bad reputation" and that women need training on how they can keep their information secure. A third subject observed that men in her field were more active and less cautious on social media, particularly when it came to sharing news about their accomplishments.

Female subjects mentioned imposter syndrome and issues of confidence several times as factors that discourage women from promoting themselves and their work using online profiles and social media. One subject stated that since women report higher rates of imposter syndrome, online profiling systems, which she viewed as more masculine, are more off-putting to women.

Two male subjects acknowledged that there was probably gender bias in scholarship, but could not give specific examples. One noted, "I'm confident there is gender bias in everything." Another acknowledged that he probably gets some male privilege, although he could not identify how gender would impact scholarly communications practices.

Two male respondents referred to "Rock Star" and "Famous" women in their fields or departments-who are referred to by their first name only and were frequently invited to serve on panels-as examples of women who are successful in academia. It is unclear though, whether women being referred to by their first name is a sign of prestige or a detriment to it. Along with many other articles and online buzz on the topic, a 2018 article in the Wall Street Journal discussed the potential implications of famous women being referred to by their first names while men are often referred to by their surnames. ${ }^{19}$ The context of the article was primarily politics, but the concept may apply in academia as well.

A third male referred to a time when, in his department, women needed to be $30 \%$ "better" than men in order to receive tenure, but that there was more equity now.

\section{Conclusions}

Of the faculty we interviewed, there was a wide range of understanding of the topics we discussed, from faculty who use online faculty profile systems, take advantage of open access, and use a range of citation metrics to those who were generally unfamiliar with the topics we discussed. We chose to interview subjects across disciplines and in varying types of faculty positions (tenured and tenure-track as well as tenureineligible) in order to gain a broad picture of what our faculty are considering in terms of these issues and the types of library support they would prefer.

Overall, our male subjects were more active in building their online presence and engaging in open access; our female subjects expressed more concerns about copyright and security online. LinkedIn was the most popular place for our faculty to be building profiles online, in order to recruit for their institutions and to keep connected with former students. Other scholarly profile systems were less universally used due to lack of time or lack of understanding of the reasons to maintain a presence in one site over another.

Our research highlighted what many others have found, that we must consider a broader range of impact data and criteria when telling the story of what our faculty have accomplished and contributed to the greater 
good. Faculty measured their success based on the success of their students both during and after college, their academic productivity or personal prestige, their societal impact, and their positive impact on educational practices.

When it comes to library services, female and male faculty highly value personalized and customized services, such as office visits and personal emails informing them of relevant services. A small number indicated interest in online generalized support as well, and perhaps some interactive or cohort-focused workshops. Most rejected the idea of attending general workshops or relying solely on online tutorials and guides.

In general, there was broad agreement among the faculty interviewed that gender comes into play in a variety of ways in academia; female subjects had an easier time describing specific examples of gender bias, but most male subjects also articulated awareness that gender issues have been detrimental to women in some way and that those issues should be addressed.

This study has shown us the need to develop a menu of services to support a broad range of faculty needs, one that takes into consideration their varied impact goals and work styles, as well as the confidence, privacy, and security concerns most strongly communicated by some of our female subjects.

\section{Future Work}

While this work has provided ideas for better serving our male and female faculty in the areas that we explored, a broader study will be developed to explore discipline and rank in addition to gender. The questions we will ask are similar to our interview questions, but elaborated upon in a fashion that will allow for deployment to a larger audience, as well as analysis through commonly available data tools.

\section{-Copyright 2019 Laura Robinson and Anna Newman}

\section{Acknowledgements}

The authors thank the 20 faculty who agreed to give precious hours of their summer research or vacation time to contribute to this work. We also thank Anna Gold for providing inspiration for this project and for her persistent enthusiasm and support throughout.

\section{Endnotes}

1. Markus Helmer, Manuel Schottdorf, Andreas Neef, and Demian Battaglia, "Gender Bias in Scholarly Peer Review," Elife 6 (2017), https://doi.org/10.7554/eLife.21718.001; Molly M. King, Carl T. Bergstrom, Shelley J. Correll, Jennifer Jacquet, and Jevin D. West, "Men Set their Own Cites High: Gender and Selfcitation Across Fields and Over Time," Socius 3 (2017), https://doi.org/10.1177\%2F2378023117738903.

2. King et al., "Men Set their Own Cites High."

3. Fred Guterl, "Diversity in Science: Why it is Essential for Excellence," Scientific American, October 1, 2014, https:/www.scientificamerican.com/article/diversity-in-science-why-it-is-essential-for-excellence/; Mathias Wullum Nielsen, Sharla Alegria, Love Börjeson, Henry Etzkowitz, Holly J. Falk-Krzesinski, Aparna Joshi, Erin Leahey, Laurel Smith-Doerr, Anita Williams Woolley, and Londa Schiebinger, "Opinion: Gender Diversity Leads to Better Science," Proceedings of the National Academy of Sciences 114, no. 8 (2017): 1740-1742; Anita Williams Woolley, Christopher F. Chabris, Alex Pentland, Nada Hashmi, and Thomas W. Malone, "Evidence for a Collective Intelligence Factor in the Performance of Human Groups," Science 330, no. 6004 (2010): 686-688.

4. Scott Talan, "Is Professorial Branding for You? Yes, it is," The Chronicle of Higher Education, October 15, 2017, https://www.chronicle.com/article/Is-Professorial-Branding-for/241438.

5. Graham Kendall, Angelina Yee, and Steven Hardy, "We Should be Just a Number and We Should Embrace it," The Electronic Library 35, no. 2 (2017): 348-357.

6. William Joseph Thomas, Barbara Chen, and Gail Clement, "ORCID Identifiers: Planned and Potential Uses by Associations, Publishers, and Librarians," The Serials Librarian 68, no. 1-4 (2015): 332-341; 
Martin Klein and Herbert Van de Sompel, "Discovering scholarly orphans using ORCID," In Proceedings of the 17th ACM/IEEE Joint Conference on Digital Libraries, June 2017: 189-198.

7. Andreas Meier and Dirk Tunger. "Survey on Opinions and Usage Patterns for the ResearchGate Platform." PloS one 13, no. 10 (2018), e0204945.

8. Julia E. Rodriguez, "Awareness and Attitudes about Open Access Publishing: a Glance at Generational Differences.” The Journal of Academic Librarianship 40, no. 6 (2014): 604-610; Jennifer Rowley, Frances Johnson, Laura Sbaffi, Will Frass, and Elaine Devine, "Academics' behaviors and Attitudes towards Open Access Publishing in Scholarly Journals," Journal of the Association for Information Science and Technology 68, no. 5 (2017): 1201-1211; Jingfeng Xia, "A Longitudinal Study of Scholars' Attitudes and Behaviors toward Open-access Journal Publishing," Journal of the American Society for Information Science and Technology 61, no. 3 (2010): 615-624, https://doi.org/10.1002/asi.21283; Olga Belikov and Robert Bodily, "Incentives and Barriers to OER Adoption: A Qualitative Analysis of Faculty Perceptions," Open Praxis 8, no. 3 (2016): 235-246, https://www.learntechlib.org/p/173537; Yimei Zhu, "Who Support Open Access Publishing? Gender, Discipline, Seniority and other Factors Associated with Academics' OA Practice," Scientometrics 111, no. 2 (2017): 557-579.

9. Yimei Zhu, "Who Support Open Access Publishing?"

10. Francisco Segado-Boj, Juan Martín-Quevedo, and Juan José Prieto-Gutiérrez, "Attitudes toward Open Access, Open Peer Review, and Altmetrics among Contributors to Spanish Scholarly Journals," Journal of Scholarly Publishing 50, no. 1 (2018): 48-70.

11. Nielsen, "Gender Inequality."

12. Peter van den Besselaar and Ulf Sandström, "Vicious Circles of Gender Bias, Lower Positions, and Lower Performance: Gender Differences in Scholarly Productivity and Impact," PloS one 12, no. 8 (2017), e0183301.

13. Anna Kaatz, Belinda Gutierrez, and Molly Carnes, "Threats to Objectivity in Peer Review: the Case of Gender," Trends in Pharmacological Sciences 35, no. 8 (2014): 371-373.

14. Helmer, "Gender Bias."

15. King, "Men Set their Own Cites High."

16. Ahmed S. M. Zabed, "Use of Electronic Resources by the Faculty Members in Diverse Public Universities in Bangladesh," The Electronic Library 31, no. 3 (2013): 290-312.

17. Julia A. Files, Janis E. Blair, Anita P. Mayer, and Marcia G. Ko, "Facilitated Peer Mentorship: a Pilot Program for Academic Advancement of Female Medical Faculty," Journal of Women's Health 17, no. 6 (2008): 1009-1015; Geoffrey M. Fleming, Jill H. Simmons, Meng Xu, Sabina B. Gesell, Rebekah F. Brown, William B. Cutrer, Joseph Gigante, and William O. Cooper, "A Facilitated Peer Mentoring Program for Junior Faculty to Promote Professional Development and Peer Networking," Academic Medicine: Journal of the Association of American Medical Colleges 90, no. 6 (2015): 819.

18. Adrianna Kezar, and Daniel Maxey, "The Changing Academic Workforce," Trusteeship 21, no. 3 (2013): $15-21$.

19. Atir S. Stav and Melissa J. Ferguson, "Do You Use Somebody's First Name or Last Name? The Answer Speaks Volumes,” Wall Street Journal, August 12, 2018, https://www.wsj.com/articles/do-you-usesomebodys-first-name-or-last-name-the-answer-speaks-volumes-1534125720. 